\title{
The effectiveness of non-surgical interventions for common plantar digital compressive neuropathy (Morton's neuroma): a systematic review and meta-analysis
}

\author{
Barry G. Matthews ${ }^{1 *}$ (D), Sheree E. Hurn ${ }^{1,2}$, Michael P. Harding ${ }^{3}$, Rachel A. Henry ${ }^{4}$ and Robert S. Ware 5
}

\begin{abstract}
Background: Morton's neuroma (MN) is a compressive neuropathy of the common plantar digital nerve. It is a common compressive neuropathy often causing significant pain which limits footwear choices and weight bearing activities. This paper aims to review non-surgical interventions for $\mathrm{MN}$, to evaluate the evidence base for the clinical management of $\mathrm{MN}$.

Methods: Electronic biomedical databases (CINAHL, EMBASE, MEDLINE and Cochrane) were searched to January 2018 for studies evaluating the effectiveness of non-surgical interventions for Morton's neuroma. Outcome measures of interest were treatment success rate (SR) (binary) and pain as measured using 100-point visual analogue scale (VAS) (continuous). Studies with and without control groups were included and were evaluated for methodological quality using the Downs and Black Quality Index. Results from randomised controlled trials (RCT) were compared between-groups, and case series were compared pre- versus post-treatment. Effect estimates are presented as odds ratios (OR) for binary data or mean differences (MD) for continuous data. Random effects models were used to pool effect estimates across studies where similar treatments were used. Heterogeneity was assessed using the $P^{2}$ statistic.
\end{abstract}

Results: A total of 25 studies met the inclusion criteria, seven RCTs and 18 pre/post case series. Eight different interventions were identified, with corticosteroid or sclerosing injections being the most often reported (seven studies each). Results from a meta-analysis of two RCTs found corticosteroid injection decreased pain more than control on VAS (WMD: -5.3, 95\%Cl: - 7.5 to - 3.2). Other RCTs reported efficacy of: manipulation/mobilisation versus control (MD: -15.3, 95\%Cl: -29.6 to - 1.0); extracorporeal shockwave therapy versus control (MD: -5.9, 95\%Cl: -21.9 to 10.1). Treatment success was assessed for extracorporeal shockwave therapy versus control (OR: 0.3, 95\%Cl: 0.0 to 7.1 ); and corticosteroid injection vs footwear/padding (OR: 6.0, 95\%Cl: 1.9 to 19.2). Sclerosing and Botox injections, radiofrequency ablation and cryoneurolysis have been investigated by case series studies, however these were of limited methodological quality.

Conclusions: Corticosteroid injections and manipulation/mobilisation are the two interventions with the strongest evidence for pain reduction, however high-quality evidence for a gold standard intervention was not found. Although the evidence base is expanding, further high quality RCTs are needed.

Keywords: Common plantar digital nerve, Morton's neuroma, Compression neuropathy, Non-surgical intervention

\footnotetext{
*Correspondence: bg.matthews@qut.edu.au

'School of Clinical Sciences, Queensland University of Technology, Kelvin

Grove, Brisbane, QLD 4059, Australia

Full list of author information is available at the end of the article
}

(c) The Author(s). 2019 Open Access This article is distributed under the terms of the Creative Commons Attribution 4.0 International License (http://creativecommons.org/licenses/by/4.0/), which permits unrestricted use, distribution, and reproduction in any medium, provided you give appropriate credit to the original author(s) and the source, provide a link to the Creative Commons license, and indicate if changes were made. The Creative Commons Public Domain Dedication waiver (http://creativecommons.org/publicdomain/zero/1.0/) applies to the data made available in this article, unless otherwise stated. 


\section{Background}

Morton's neuroma (MN) is a compressive neuropathy of the common plantar digital nerve, most commonly occurring in the third web space, followed by the second and then the fourth [1-10]. The plantar nerve enlargement was first described in 1835 [11], the symptoms in 1845 [12] and the condition was initially called metatarsalgia in 1876 by Thomas Morton whose name is now associated with the condition [13]. Affecting 88 in every 100,000 women and 50 in every 100,000 men presenting for primary care in the United Kingdom, it is the most common compressive neuropathy after carpal tunnel syndrome [14].

People with MN usually describe abnormal forefoot sensations such as a burning or ache [15]. Pain localisation is most common in the plantar aspect of the forefoot, followed by the toe(s) and then the dorsal web space [16]. Diagnosis can reliably be made based on clinical presentation and testing [15] with ultrasound proposed as an accurate and cost-effective imaging method to confirm the diagnosis, especially in cases where the clinical diagnosis is equivocal [17]. Ultrasound without a clinical diagnosis may lead to a false diagnosis of $\mathrm{MN}$ for asymptomatic interdigital nerve enlargements [18].

Confusion surrounds the name $\mathrm{MN}$, with many alternative descriptions for the condition (e.g. intermetatarsal neuroma [5, 19], intermetatarsal neuritis [5], plantar interdigital neuroma $[1,7,20]$, interdigital neuroma [3, $4,10,21]$, interdigital neuralgia [22], interdigital neuritis [23] and plantar digital neuralgia [2]) and no histological evidence of a true neuroma with axonal degeneration and collagen proliferation [24].

Non-surgical interventions for $\mathrm{MN}$ are a recommended treatment option before surgery [25-28]. Clinicians also encounter health consumers who either decline surgical intervention or, due to contraindications, are not suitable for surgery. A comprehensive review of the non-surgical interventions would benefit all clinicians managing this cohort. Clinicians may recommend a range of treatments for MN. Current published treatment pathways for the non-surgical management of $\mathrm{MN}$ are based on a combination of one RCT [3], a number of pre/post case series, and expert opinion. These pathways follow a staged care approach from wider, low heeled footwear and metatarsal padding [25-28], foot orthoses [26, 29] or oral non-steroid or steroid medications [26] to corticosteroid injections [25-30], sclerosing injections [25-28] or extracorporeal shockwave therapy (ESWT) [26] and end with surgical interventions [25-30] including cryoneurolysis [25, 26]. However, at present there is no clarity surrounding which treatment options are most effective and no standard practice around which treatment should be considered the gold standard.
A 2004 Cochrane review that assessed interventions for $\mathrm{MN}$ included three randomised controlled trials (RCT), with two surgical and one non-surgical intervention [31]. The review concluded there was insufficient evidence to assess the effectiveness of interventions for MN. Another systematic review, based on a 2015 search, concluded that the effectiveness of non-surgical treatments appears less than surgical but "the paucity of adequate studies makes it hard to assess" [32]. The review evaluated one RCT, one prospective comparative study and 10 case series across four different non-surgical interventions. Several studies have been published on $\mathrm{MN}$ interventions since 2015, but no subsequent systematic review assessing the quality of these studies or the effectiveness of the interventions has been published. An up-to-date synthesis of the available evidence is needed to assist clinicians in selecting the most effective treatments when managing patients with MN. The aim of this systematic review is to appraise and synthesise the evidence from a wide range of study designs investigating non-surgical interventions for $\mathrm{MN}$.

\section{Methods \\ Clinical question}

To identify studies relating to non-surgical treatment of $\mathrm{MN}$, a clinical question was defined using the population, intervention, comparison, outcome and study type (PICOS) format prior to establishing the search strategy. Population was defined as adults aged 18 years or older with a MN diagnosed through clinical symptoms, ultrasound or magnetic resonance imaging, without a history of significant trauma, foot surgery or systemic inflammatory conditions such as rheumatoid arthritis. Intervention was defined as any non-surgical intervention that aimed to reduce pain associated with MN. Surgery was defined as an incision into the body [33], thus non-surgical would include skin penetration interventions not involving an incision such as an injection or skin penetrating probe. The comparison was considered to be a control, or placebo group, or another non-surgical intervention compared to the primary intervention. Primary outcomes included pain or function, and secondary outcomes included intervention adverse events, change in neuroma size and quality of life. Included study types were experimental studies from level II (randomised controlled trials) to IV (case series with either post-test or pre-test/post-test outcomes) of the Australian National Health and Medical Research Council (NHMRC) Hierarchy of Evidence [34].

\section{Registration and reporting}

The systematic review protocol was registered with the International Prospective Register of Systematic Reviews (PROSPERO) on 07 April 2016, registration no. 
CRD42016037405. The study has been reported according to the Preferred Reporting Items for Systematic Reviews and Meta-Analyses (PRISMA) recommendations to ensure transparent and complete reporting [35]. The types of studies to be included when the protocol was registered were the NHMRC study levels II through to III-3 [34], but the review group decided to include level IV studies due to the paucity of higher level evidence identified in initial searches.

\section{Information sources and search}

The search was conducted up to 15 January 2018 for the following biomedical databases: CINAHL, EMBASE, Medline and Cochrane Central Register of Controlled Trials. A filter for human and English language studies was applied, without date restriction. The complete search strategy for Medline is shown in Table 1. Hand searching of reference lists of included studies was also conducted.

\section{Study selection}

All records retrieved by the search were independently screened by title and abstract (BM and $\mathrm{MH}$ ) for relevance to the review question, then all potentially relevant studies underwent full text screening (BM, RH and $\mathrm{MH})$. The PICOS clinical question described above formed the inclusion criteria by which detailed full-text evaluation was performed to determine which studies

\begin{tabular}{|c|c|}
\hline \# & Searches \\
\hline 1 & $\begin{array}{l}\text { peripheral nervous system neoplasms/ OR nerve compression } \\
\text { syndromes/ OR nerve sheath neoplasms/ OR neuralgia/ } \\
\text { OR neuritis/ OR (neuralgia\$1 OR neuritis OR entrapment\$1 } \\
\text { OR (nerve ADJ5 compression)).ti,ab. }\end{array}$ \\
\hline 2 & $\begin{array}{l}\text { neurilemmoma/ OR neuroma/ OR neurofibroma/ OR } \\
\text { (neurilemmoma\$1 OR neuroma\$1 OR neurofibroma\$1).ti,ab. }\end{array}$ \\
\hline 3 & foot diseases/ OR foot/ OR forefoot/ OR (foot OR forefoot).ti,ab. \\
\hline 4 & $\begin{array}{l}\text { metatarsus/ OR metatarsal bones/ OR metatarsophalangeal joint/ } \\
\text { OR toes/ OR (metatarsus OR metatarsal\$1 OR intermetatarsal OR } \\
\text { metatarsophalangeal OR toe\$1 OR interdigital OR (plantar ADJ5 } \\
\text { digital)).ti,ab. }\end{array}$ \\
\hline 5 & $\begin{array}{l}\text { (morton\$1 ADJ5 (disease\$1 OR neuroma\$1 OR neuralgia\$1)).ti,ab. } \\
\text { OR metatarsalgia/ OR metatarsalgia\$1.ti,ab. }\end{array}$ \\
\hline 6 & 1 OR 2 \\
\hline 7 & 3 OR 4 \\
\hline 8 & 6 AND 7 \\
\hline 9 & 5 OR 8 \\
\hline 10 & exp animals/ NOT humans.sh. \\
\hline 11 & 9 NOT 10 \\
\hline 12 & $\begin{array}{l}\text { (treat } \$ 5 \text { OR intervention } \$ 2 \text { OR therap } \$ 5 \text { OR manag } \$ 5 O R \\
\text { procedur } \$ 2) . t i, a b .\end{array}$ \\
\hline 13 & 11 AND 12 (apply English language filter) \\
\hline
\end{tabular}

would be included in the review. Disagreements between the independent reviewers during study selection were resolved by a fourth reviewer $(\mathrm{SH})$. The recommended PRISMA flow summary diagram [35] for the search strategy is shown in Fig. 1.

\section{Data collection process}

A data collection form was developed and one reviewer (BM) extracted the data while a second reviewer (RH) checked the accuracy of the extracted data. A third reviewer (RW) provided clarification over data formats or data conversion. Data were extracted from each included study on (1) characteristics of study participants (including number of study participants, sex, age); (2) type of intervention (including type, technique, duration and frequency); (3) study methods (neuroma diagnosis method, type of outcome measure, length of follow up); and (4) study design (using the NHMRC Hierarchy of Evidence [34]). A study was defined as experimental if there were two parallel study groups, with allocation to group decided on either a randomised or quasi-randomised basis. A study was defined as an uncontrolled case series if there were at least two measurements (one pre-treatment and one post-treatment) in the same treatment group, with no concurrent comparison group. Numerical data were extracted, including number of participants in each group and frequency of successful outcomes for categorical data or mean and standard deviation for continuous data.

\section{Risk of bias in individual studies}

All included studies were independently reviewed in full text for methodological quality (BM and $\mathrm{MH}$ ) using the 27-item Downs and Black Quality Index [36]. Rating disagreements between the independent reviewers during study selection were resolved by a third reviewer $(\mathrm{SH})$. The Quality Index provides a profile of each study's methodological strengths and weaknesses. It has good test-retest $(r=0.88)$ and inter-rater $(r=0.75)$ reliability and can be used in both experimental and observational studies [36]. The Quality Index has previously been used to report the score with a Quality Index range of low, moderate and high [37].

For this systematic review all 27 items in the original Quality Index were used. Items one to four and six to 26 were given a maximum score of one point, item five a score of two points, and item 27 was scored on a $0-5$ scale, to give a maximum possible score of 32 . Item 27 was scored by calculating the post-hoc power of the study based on defining a minimal important difference of ten points on a $0-100$ scale, extracting the standard deviation observed in the study, and specifying alpha $=0.05$. Quality Index points associated with post-hoc study powers were zero ( $<60 \%$ power), one (60 to $<80 \%$ power), two (80 to $<90 \%$ power), three ( 90 to $<95 \%$ power), four (95 to $<99 \%$ power), five ( $>99 \%$ power) [38]. 


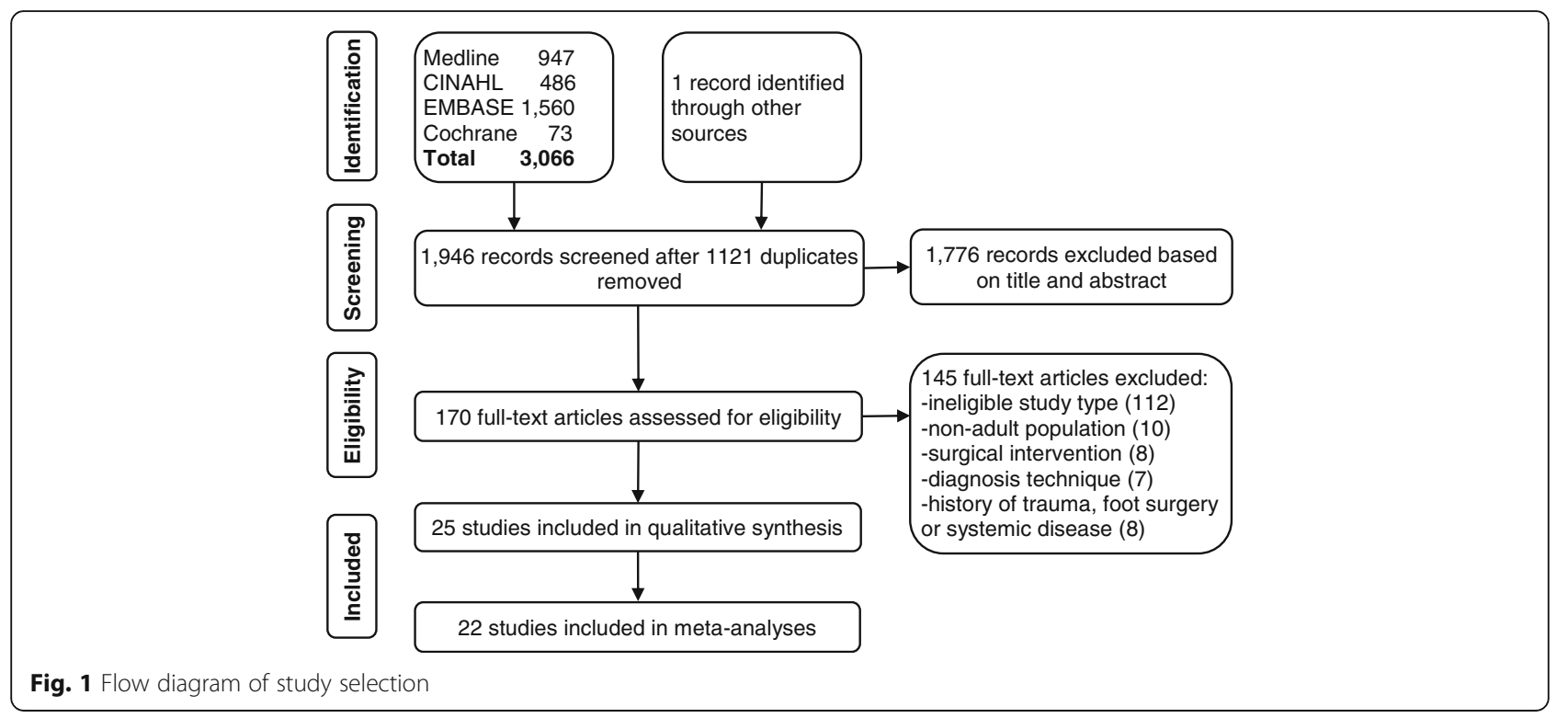

While no published data investigating the minimal important difference for $\mathrm{MN}$ was found, Thomson et al. [39], used a ten point change, Mahadevan et al. [40], a 15 point and Lizano-Diez et al. [41], a 30 point change on a $0-100$ pain visual analogue scale (VAS). A VAS is a straight line, the ends of which are defined as the extreme limits of the sensation to be measured such as pain [42].

\section{Summary measures and synthesis of results}

Raw results were extracted and when required, data were dichotomised into treatment success/failure. Interventions were categorised into groups of similar interventions, i.e. interventions with similar therapeutic targets or mechanisms (e.g. same class of drug used). Outcome measures were considered appropriate for synthesis if measuring the same construct (e.g. pain) and having a scale that could be combined for analysis (e.g. both continuous scales). The primary measure of treatment effect for binary data were odds ratio (OR) (experimental studies) or success rate (SR) (case series). The primary measure of treatment effect for continuous data were mean difference (MD) (for both experimental studies and case series). When estimating the MD for pre/ post scores a correlation of 0.5 between pre and post measurements was assumed. When results from two or more studies are combined in a meta-analysis, overall estimates of effect are presented as weighted odds ratio, weighted success rate (WSR), or weighted mean difference (WMD) as appropriate. The precision of effect estimates was characterised using $95 \%$ confidence intervals (CI). Random effects models were used to pool treatment effects, and heterogeneity of clinical and methodological diversity was assessed with the $I^{2}$ statistic [43]. Analyses were carried out separately for experimental studies and case series. For experimental studies with parallel groups, the between-group post-treatment scores were compared. For studies with pre/post data, if data were extracted from a case series, the within-group pre/post scores were compared, and if data were extracted from an experimental study with parallel-groups then the pre/post scores from the intervention arm were compared. The data for the RCT meta-analysis only includes RCT data and the pre/post case series meta-analyses only includes pre/post case series data.

A clinical evidence summary (Fig. 2) was created using the traffic light tool to clearly display the key findings from the review. The traffic light tool has been rated as significantly more useful than the United Kingdom National Health Service recommended "situation, background, assessment, recommendation" system for communication within medical teams [44]. The traffic light tool has previously been used as a communication tool with health professionals for the management of foot care in diabetes [45] and the paediatric flat foot [46]. The figure and traffic light tool categorise interventions into three groups; (i) green to indicate an intervention with a high level of evidence (RCT or meta-analysis of RCTs) and a statistically significant reduction in pain, (ii) red to indicate an intervention with a high level of evidence (RCT or meta-analysis of RCTs) and no statistically significant reduction in pain, or (iii) amber for all interventions that don't align with the green or red categories. The traffic light tool may be used in combination with the existing published treatment pathways for $\mathrm{MN}$ [25-30] when considering a non-surgical intervention. Study quality, effect size, adverse events (benefit versus harm), clinician experience, and the predicaments, rights, and preferences of the individual with 


\begin{tabular}{|c|c|c|c|}
\hline & Intervention type & Traffic light tool & $\begin{array}{c}\text { Statistically significant pain } \\
\text { reduction }^{\#}\end{array}$ \\
\hline \multirow{4}{*}{ 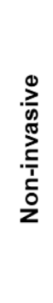 } & \multirow{3}{*}{$\begin{array}{l}\text { Wider footwear and metatarsal padding } \\
\text { Extracorporeal shockwave therapy }\end{array}$} & RCT & Yes at 1.5 months \\
\hline & & $\mathrm{RCT}$ & Pain not reported \\
\hline & & $\mathrm{RCT}$ & No at 1 month \\
\hline & Varus/valgus foot wedge ${ }^{*}$ & $\mathrm{RCT}$ & No at 12 months \\
\hline \multirow{5}{*}{ 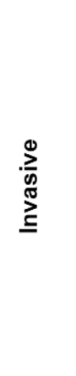 } & Corticosteroid injections & Meta-analysis of $2 \mathrm{RCTs}$ & Yes at 3-6 months (2 studies) \\
\hline & Sclerosing injections & Case series & Yes at 12 months (4 studies) \\
\hline & Radiofrequency ablation & Case series & Yes at 7 months ( 3 studies) \\
\hline & Cryoneurolysis & Case series & Pain not reported (2 studies) \\
\hline & Botox injection & Case series & Yes at 3 months ( 1 study) \\
\hline & \multicolumn{3}{|c|}{$\begin{array}{l}\text { Green indicates an intervention with a high level of evidence (RCT or meta-analysis of RCTs) and a statistically significant reduction in pain. } \\
\text { Red indicates an intervention with a high level of evidence (RCT or meta-analysis of RCTs) and no statistically significant reduction in pain. } \\
\text { Amber indicates an intervention that does not align with the green or red categories (low level evidence or no evidence for the intervention). }\end{array}$} \\
\hline \multicolumn{4}{|c|}{$\begin{array}{l}\text { Fig. } 2 \text { Clinical evidence summary: Morton's neuroma non-surgical interventions for pain reduction. RCT Randomised controlled trial; Clinical } \\
\text { evidence summary may be used in combination with the existing published treatment pathways for Morton's neuroma; *No studies assessing } \\
\text { the effect of orthoses on foot function related to Morton's neuroma were found by the review; "\#Statistically significant reduction in pain may not } \\
\text { be a clinically significant reduction in pain (no data on the minimal important difference for pain reduction in Morton's neuroma was found) }\end{array}$} \\
\hline
\end{tabular}

MN will need to be balanced by the clinician in their decision making process [47].

\section{Results}

\section{Overview of studies}

The search identified 1946 potential titles and abstracts to screen after the removal of 1121 duplicates. Of the 170 studies requiring full text review, 25 were included [1-10, 19, 20, 22, 23, 39-41, 48-55]. The most common reason for excluding studies following full-text review was ineligible study type (112 studies). A flow diagram of the study selection process is presented in Fig. 1. Included studies encompassed a total of 1974 study participants and 2100 neuromas. Studies took place in United Kingdom (6 studies) [2, 7, 22, 39, 40, 50], Italy (5 studies) $[8,20,23,53,55]$, United States of America (4 studies) $[4,5,19,49]$, Australia [1, 10], South Korea [52, 54], Spain [6, 41] and Turkey [3, 9] (2 studies each) and South Africa [48] and France [51] (1 study each). Clinical settings represented were Hospital (9 studies) [3, 8, 9, 22, 39, 41, 50, 52, 54], University [2, 6, 19, 20, 23, 48, 56] and Radiology [1, 7, 10, 49, 51, 53, 55] (7 studies each), and Private Practice (2 studies) [4, 5]. The study types consisted of seven RCTs [3, 39-41, 48, 50, 52], and 18 pre/post case series [1, 2, 4-10, 19, 20, 22, 23, 49, 51, 53-55].

\section{Outcome measures}

Pain was measured by VAS in 18 studies [2, 6-10, 19, 23, 39-41, 48, 50-55]. All 0-10 point VAS were scaled to 0-100 point for data synthesis. Alternative categorical outcome measures included the Johnson scale [57] in nine studies [1, 7, 20, 22, 40, 41, 51, 52, 54] or overall satisfaction, improvement, treatment response or symptom relief. For the purposes of analysis, a treatment measured using the Johnson scale was classified as a success if the participant recorded "completely satisfied" and as a failure otherwise. Raw results are presented fully (Additional file 1). Outcomes were dichotomised as success/failure for meta-analysis. The mean time between treatment initiation and outcome recording was 9.9 months (3 weeks to 56 months).

\section{Types of intervention}

The non-surgical interventions identified were divided into two categories: non-invasive (no skin penetration) and invasive. The non-invasive interventions included two mobilisation and manipulation studies [2, 48], two wider footwear and metatarsal padding studies [3, 4], one extracorporeal shockwave therapy (ESWT) study [52] and one orthoses study [50]. The invasive interventions included seven corticosteroid injection 
studies [1, 3, 22, 39-41, 54], seven sclerosing injection studies $[5,7,8,19,20,23,55]$, three radiofrequency ablation studies $[9,10,53]$, two cryoneurolysis studies [49, 51], and one Botox injection study [6]. See Table 2 for the study characteristics and Table 3 for the results of included studies. Overall recommendations arising from the meta-analysis using the traffic light tool are displayed in Fig. 2. Where studies were combined in meta-analysis, high levels of heterogeneity were generally observed, particularly for meta-analysis of pre/post studies; $I^{2}$ values for metaanalyses are displayed in Figs. 3, 4, 5, 6 and 7.

\section{Quality of included studies}

The quality assessment of individual studies can be viewed in Table 4. One study was rated as high, eight as moderate and 16 as low using the Quality Index, demonstrating a paucity of high-quality studies for the review to assess. Fifteen case series and one RCT study were rated as low. All studies were representative in terms of the staff and facilities where the public would normally receive the included interventions (Item 13). One study [10] did not report the main outcomes (Item 2) and another study [49] did not report participant characteristics (Item 3). Only four studies [39-41, 52] attempted to blind those measuring intervention outcomes (Item 15) and none concealed randomisation from staff until recruitment was complete (Item 24). Only Thomson et al. [39], achieved an adequate level of power allowing generalisability of results (Item 27).

\section{Non-invasive interventions}

\section{Manipulation/mobilisation}

Manipulation/mobilisation (involving distraction and plantarflexion of the metatarsophalangeal joints and mobilisation of other foot and ankle joints as required) was reported in two studies $[2,48]$. One study was an RCT [48] that showed an effect in favour of the treatment over control at 6 weeks (MD: $-15.3,95 \% \mathrm{CI}$ : -29.6 to 1.0) (Fig. 4) and the other was an uncontrolled pre/post study [2] (Table 3). The two studies showed a pre/post reduction in pain at the end of the sixth treatment, mean 5.5 weeks (range 3 to 8 ) (WMD: -44.8 , 95\%CI: -85.2 to -4.3 ) (Fig. 6).

\section{Wider footwear and metatarsal padding}

Properly fitted footwear with a wide toe box, low heel and a metatarsal pad was assessed in two studies [3, 4]. An RCT [3] showed a statistically significant success rate where the odds of a non-ultrasound guided (NUG) corticosteroid injection and anaesthetic (intervention) being successful were 6 times greater than the odds of footwear and padding (control) being successful at 6 months (OR: 6.0, 95\%CI: 1.9 to 19.2) (Fig. 5). The other was an uncontrolled pre/post study [4]. Combining these two studies showed footwear and padding to be successful in $32 \%$ of participants at a mean of 4.5 months (range 3 to 6) (WSR: 32, 95\%CI: 25 to 40\%) (Fig. 7).

\section{Extracorporeal shockwave therapy}

One study investigated ESWT, which involves microsonic energy (shockwave) pulses delivered to the plantar forefoot [52]. An RCT comparing ESWT to sham ESWT showed no statistically significant treatment effect for ESWT at 1 month review (OR: 0.3, 95\%CI: 0 to 7.1) (Fig. 5), and no statistically significant reduction in pain (MD: $-5.9,95 \% \mathrm{CI}:-21.9$ to 10.1 ) (Fig. 4). Additional results are available in Figs. 6 and 7.

\section{Varus/valgus foot wedge}

The varus/valgus foot wedges used in the study were a cobra style hard compressed felt padding adhered to the plantar surface of a fibreboard insole to supinate or pronate the foot. These were worn in the participant's usual footwear (low heeled lace-up or loose fitting slip on shoes) [50]. This RCT comparing the foot wedges showed no statistically significant treatment effect by the varus wedge over the valgus wedge at a 12 month review (MD: 10.0, 95\%CI: -19.2 to 39.2) (Fig. 4). Additional results are available in Fig. 6.

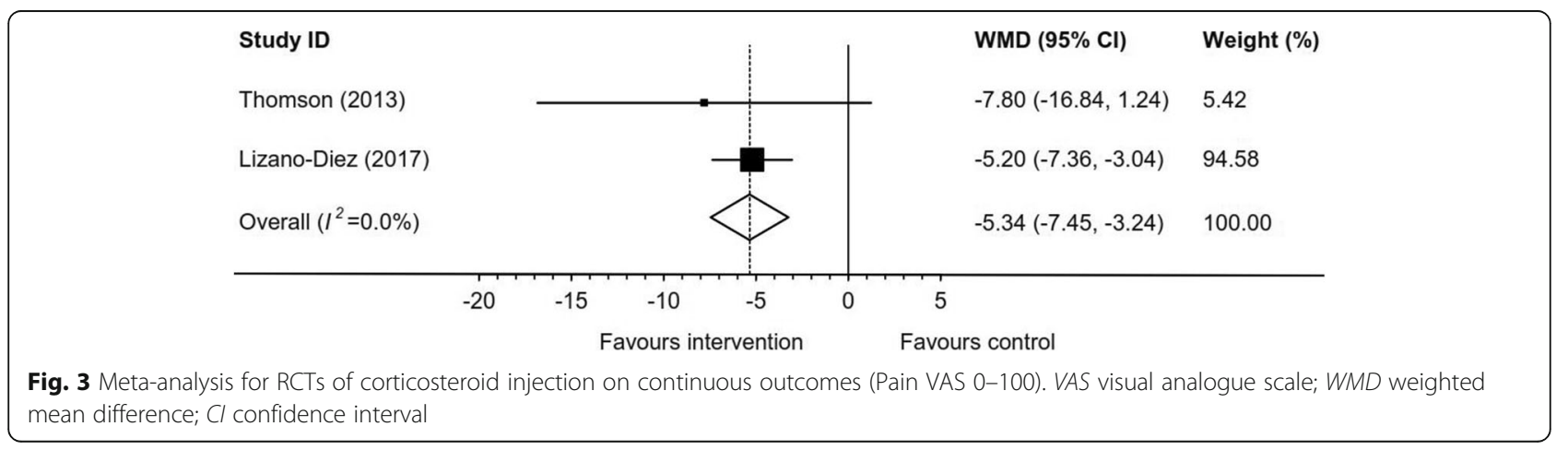




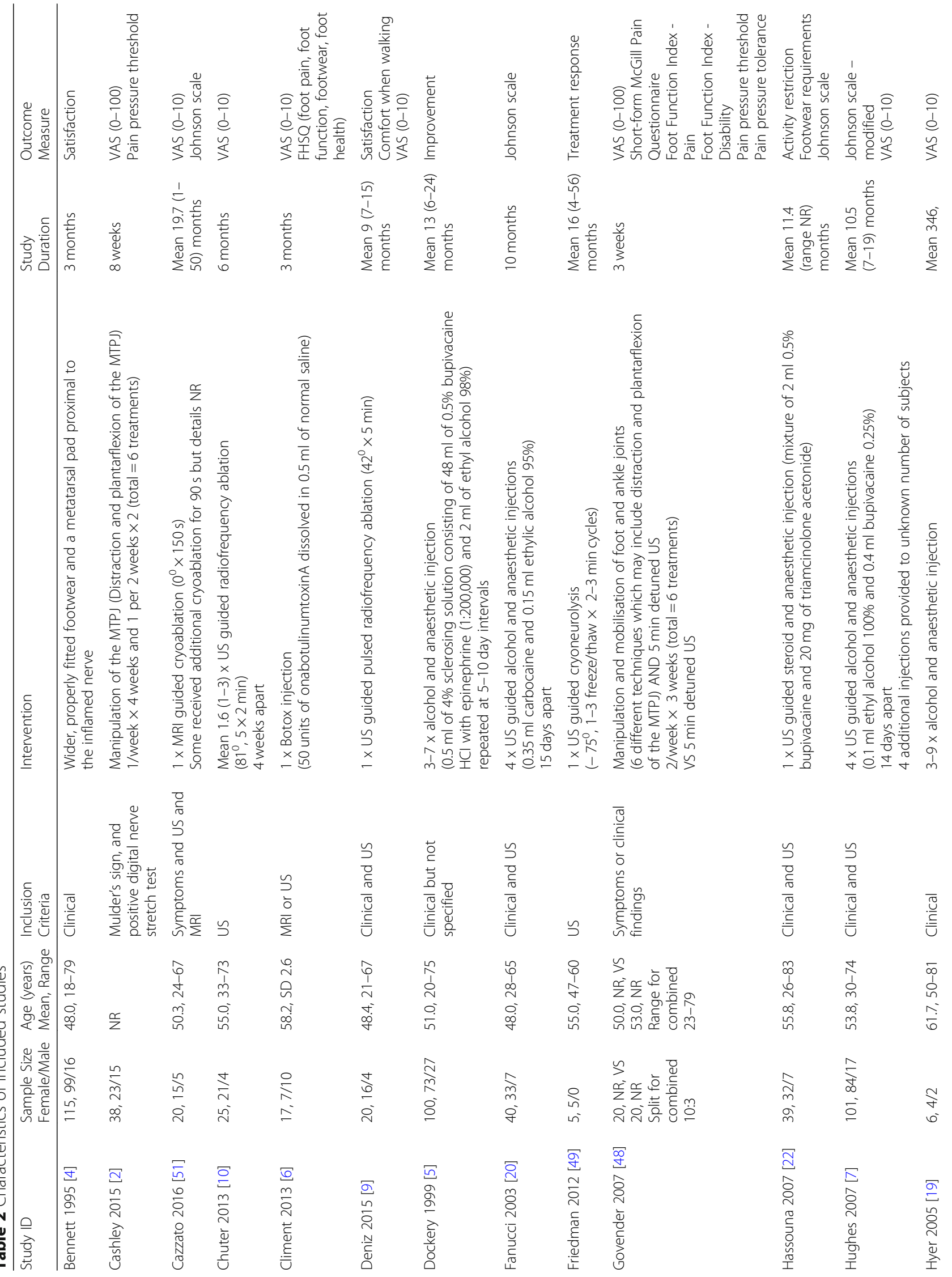




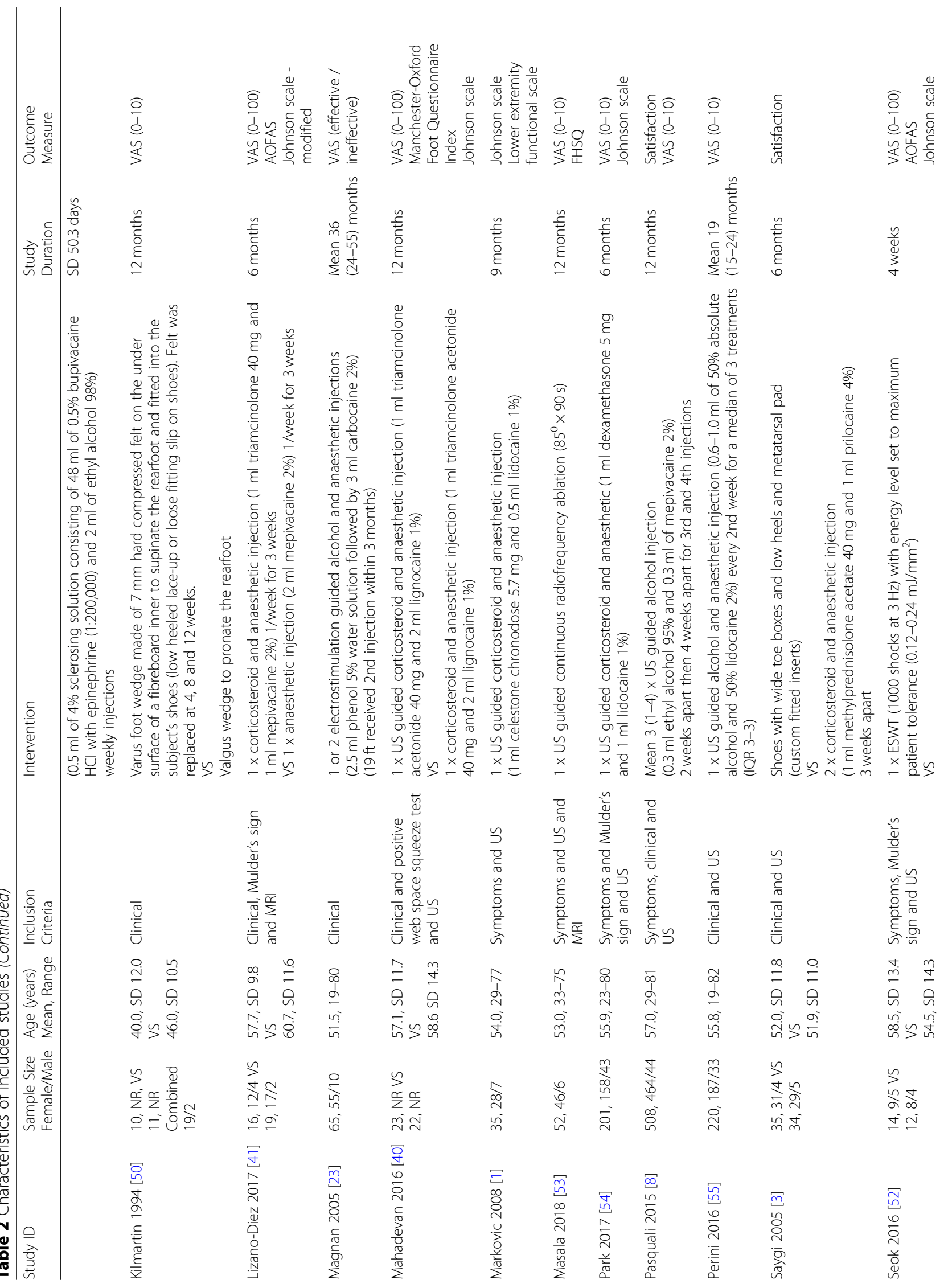




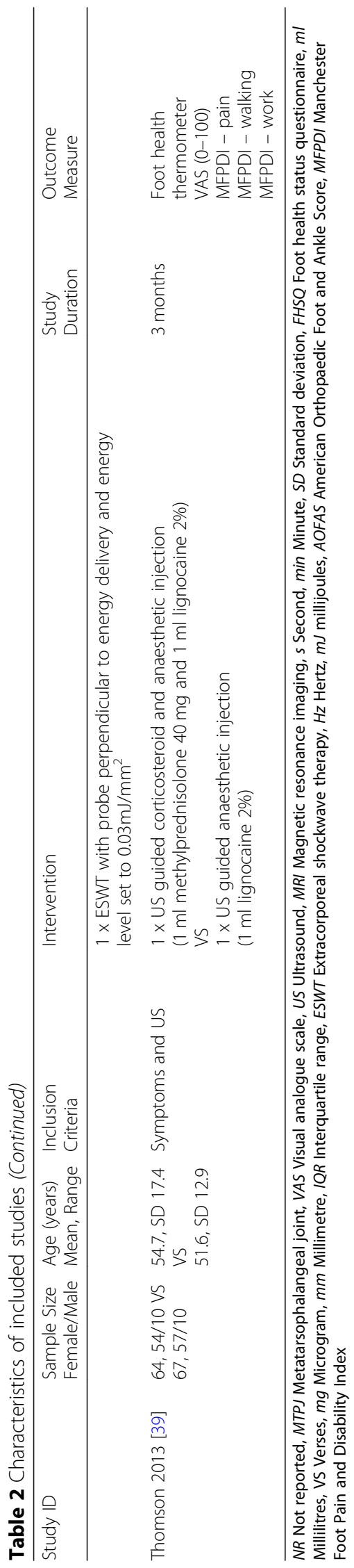




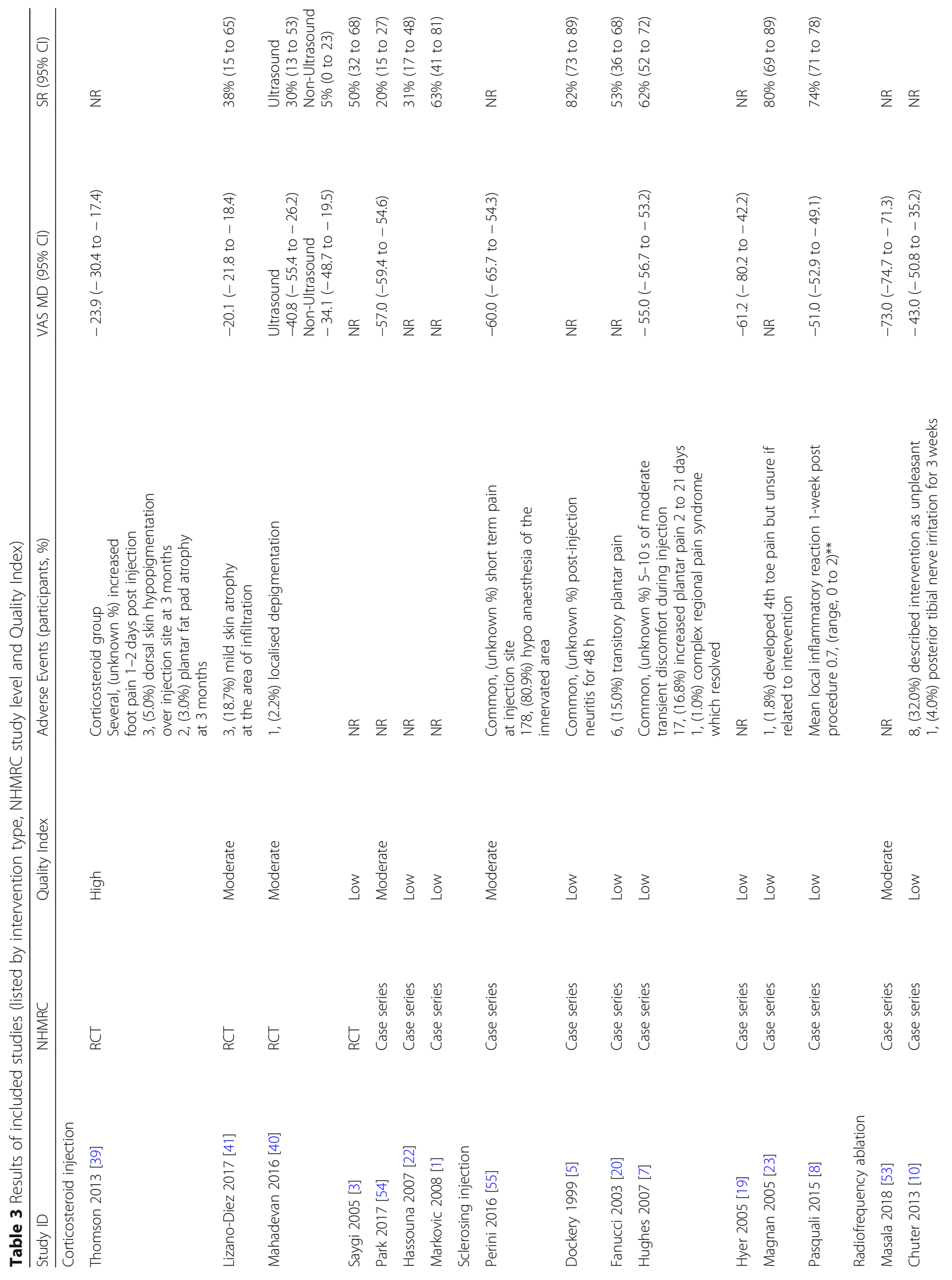




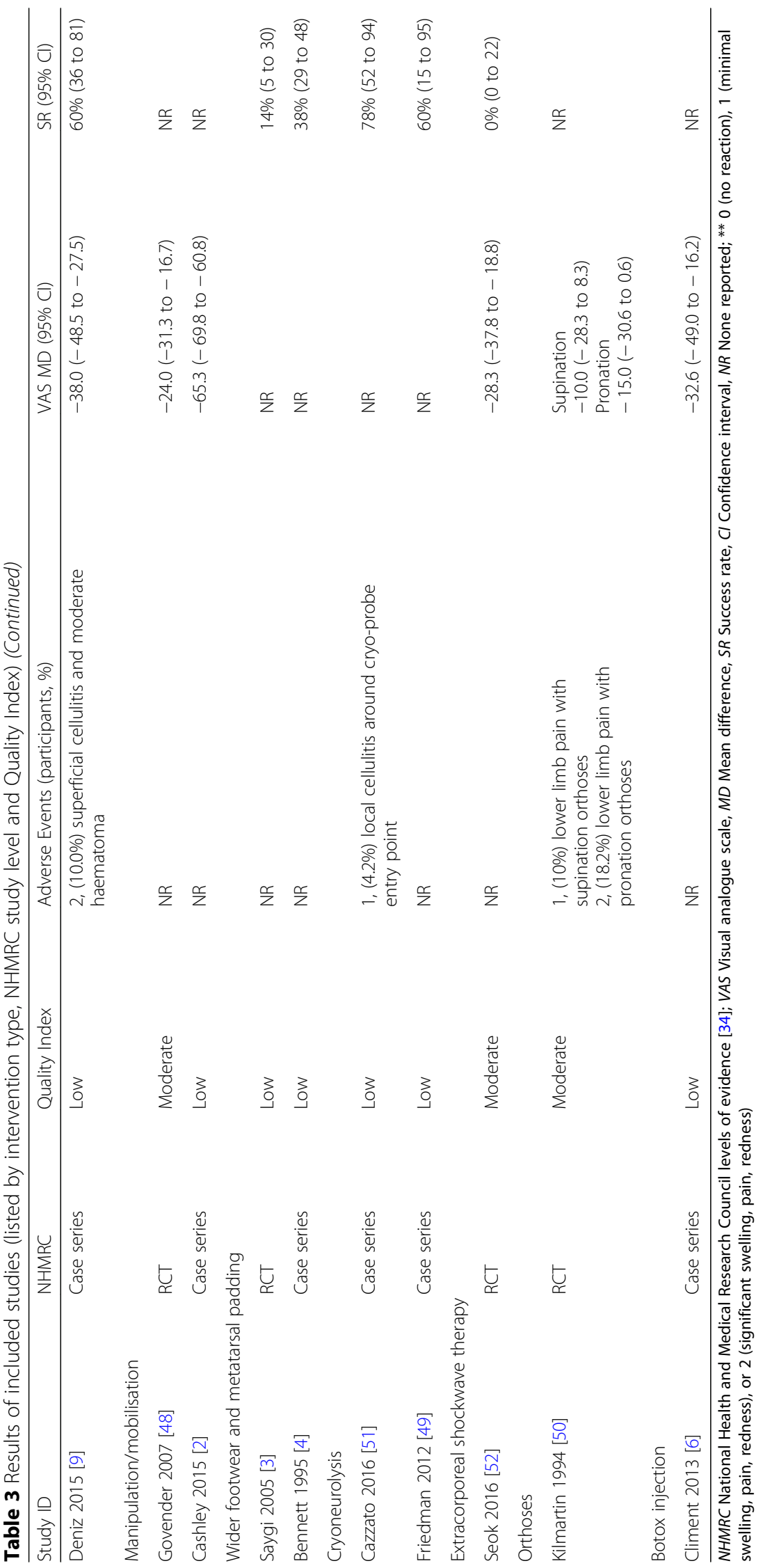




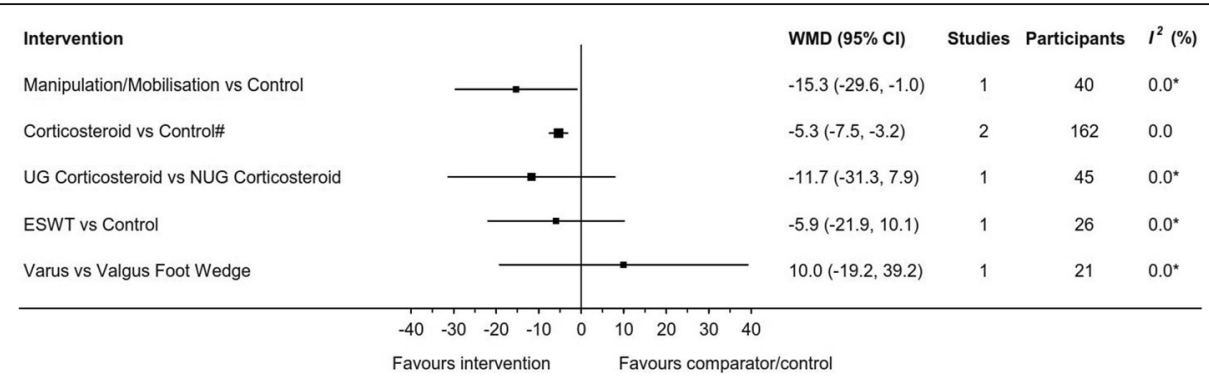

Fig. 4 Mean difference (with 95\% CI) for RCT continuous outcomes (Pain VAS 0-100). * Two or more studies required to calculate $P$ statistic; \#UG single injection and NUG three injections outcome data combined; VAS visual analogue scale; MD mean difference; Cl confidence interval; UG ultrasound guided; NUG non-ultrasound guided; ESWT extracorporeal shock wave therapy

\section{Invasive interventions}

\section{Corticosteroid injection}

A corticosteroid and anaesthetic injection at the site of the neuroma was investigated by seven studies. Three studies were RCTs, one comparing ultrasound guided (UG) corticosteroid and anaesthetic injection to UG anaesthetic injection [39], a second comparing NUG corticosteroid injection to NUG anaesthetic injection [41] and a third study comparing UG to NUG corticosteroid injection [40]. The remaining three studies of UG corticosteroid injections were uncontrolled case series [1, 22, 54]. Meta-analysis of two trials [39, 41] comparing corticosteroid and anaesthetic injection combined against anaesthetic injection alone (mean follow-up time $=4.5$ months; range 3 to 6 ) favoured the combined intervention (WMD: -5.3 , 95\%CI: -7.5 to 3.2) (Fig. 3). Additional results from RCTs are displayed in Figs. 4 and 5. Continuous outcome measures for four studies [39-41, 54] showed a pre/post reduction in pain at a mean of 6.8 months (range 3 to 12) (WMD: -34.6, 95\%CI: -58.1 to -11.2 ) (Fig. 6). Binary outcome measures with six studies [1, 3, 22, 40, 41, 54] demonstrated success following intervention at a mean of 8.4 months (range 6 to 12) (WSR: 34, 95\%CI: 21 to 49\%) (Fig. 7).

\section{Sclerosing injection}

Seven studies evaluated sclerosing injections, which involved either an UG (4 studies) [7, 8, 20, 55] or NUG (3 studies) [5, 19, 23] injection of a sclerosing compound combined with local anaesthetic. Sclerosing compounds included ethyl alcohol (6 studies) [5, 7, 8, 19, 20, 55] or phenol (1 study) [23]. The number of injections ranged from one to nine over a period of up to 3 months. All seven studies were uncontrolled pre/post studies. Four of the seven studies $[7,8,19,55]$ using continuous outcome measures showed a pre/post reduction in pain after a mean 13.4 months (range 7 to 24) review period (WMD: $-54.8,95 \% \mathrm{CI}$ : -58.5 to -51.0 ) (Fig. 6). Five of the seven studies $[5,7,8,20,23]$ with binary outcome measures showed success favoured sclerosing injections after a mean 16.3 months (range 6 to 55) review period (WSR: 72, 95\%CI: 68 to $80 \%$ ) (Fig. 7).

\section{Radiofrequency ablation}

Three studies [9, 10, 53] utilised radiofrequency ablation, where an UG probe is inserted into the neuroma and heated for a pulsed or continuous treatment. All studies had a pre/ post design with no control group. The three studies showed treatment effects in favour of the intervention, (WMD: -51.7, 95\%CI: -77.1 to -26.3 ) after a mean review period of 7 months (range 6 to 15 ) (Fig. 6).

\section{Cryoneurolysis}

Two studies [49, 51] investigated cryoneurolysis, where an UG probe is inserted into the neuroma for one to three freeze/thaw treatment cycles. Both were

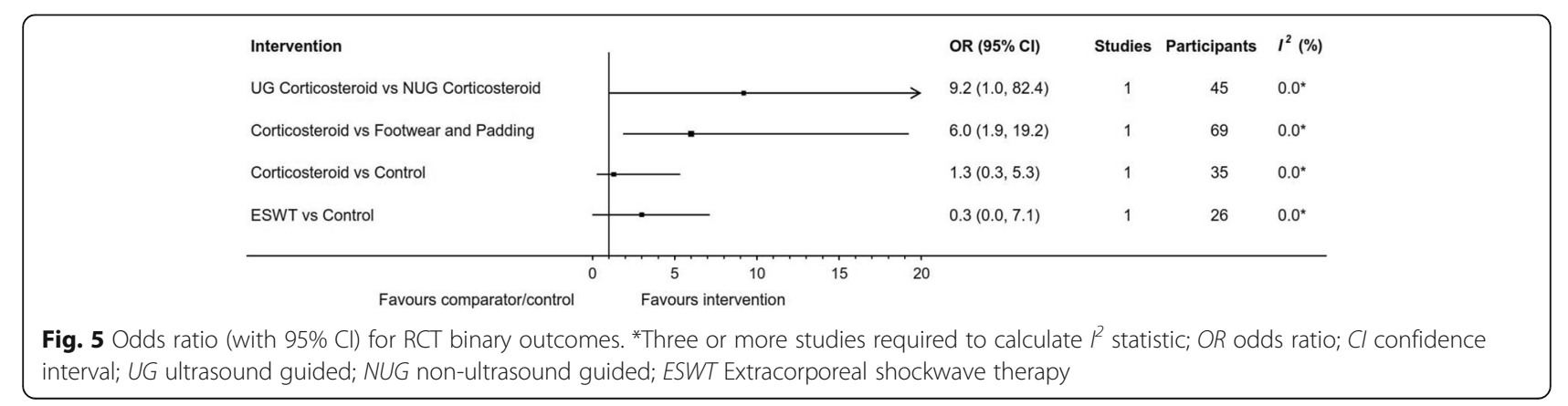




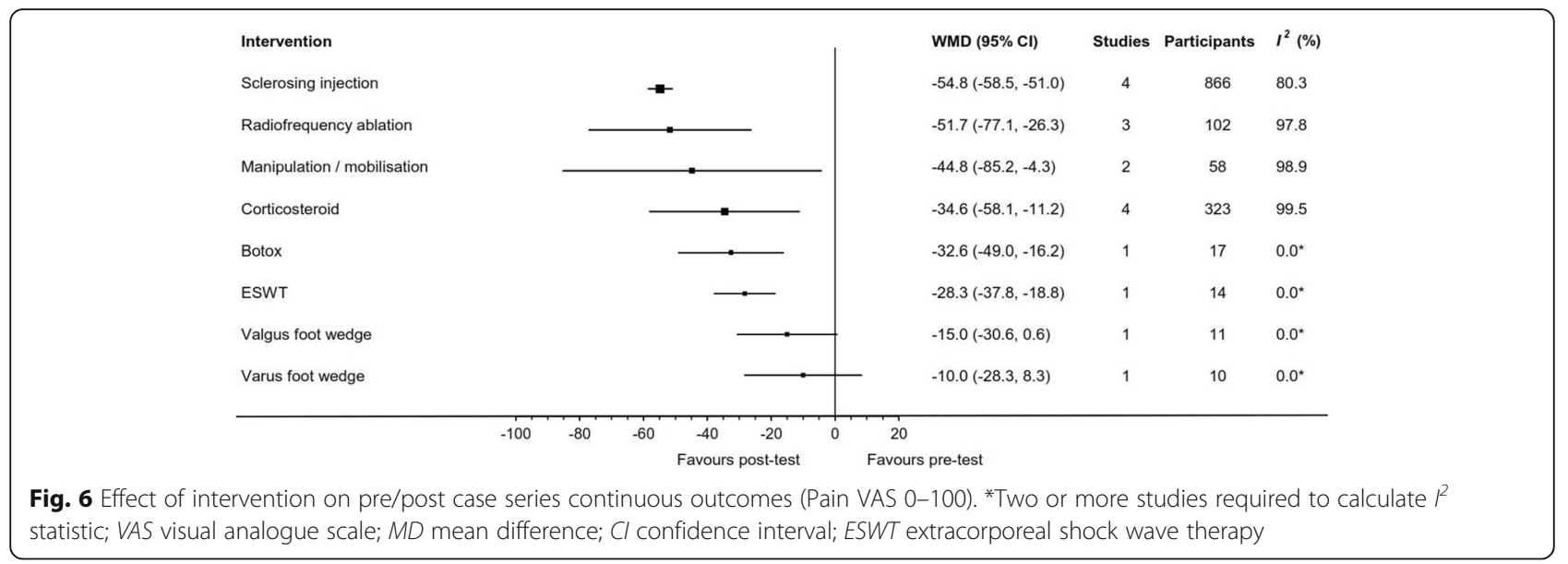

uncontrolled pre/post studies. Two studies showed the success rate favoured treatment (WSR: 75, 95\%CI: 54 to $92 \%$ ) after a mean review period of 11.4 months (range 1 to 50 ) (Fig. 7).

\section{Botox injection}

One study evaluated a NUG single injection of 50 units of onabotulinumtoxinA dissolved in $0.5 \mathrm{ml}$ of normal saline [6]. The study had an uncontrolled pre/ post design with 17 participants showed treatment effects in favour of the intervention (WMD: -32.6, 95\%CI: -49.0 to -16.2 ) after a review period of 3 months (Fig. 6).

\section{Change in neuroma size}

Four studies [7, 10, 20, 52] used ultrasound to report on change in neuroma size. Ultrasound has been reported as a reliable modality to measure neuroma size [58]. Three case series [7, 10, 20] reported on pre/post intervention change in symptomatic neuroma size and one experimental study [52] reported on post change between groups. Fanucci et al. [20], reported a pre/post mass volume reduction of at least $20 \%$ in 21 of 40 participants with UG sclerosing injections. These 21 participants were the only participants to report "complete satisfaction" on the Johnson scale. Hughes et al. [7], found a pre/ post reduction in diameter of $30 \%$ in 30 of 101 participants with UG sclerosing injections. Chuter et al. [10], was unable to compare pre/post change in diameter due to the much less distinct and ill-defined neuroma appearance after UG radiofrequency ablation. Seok et al. [52], comparing ESWT to control reported the mean diameter in both groups slightly reduced post intervention but no statistically significant difference was found.

\section{Adverse events}

No adverse events were reported for mobilisation and manipulation [2, 48], wider footwear and metatarsal padding [3, 4] or Botox injection interventions [6] (Table 3). Corticosteroid injections [39-41], sclerosing injections $[5,7,8,20,23,55]$, radiofrequency ablation $[9,10]$, cryoneurolysis [51] and orthoses [50] all reported adverse events. The most common event being pain during and post sclerosing injection $[5,7,8,20,23,55]$ and the most serious being dorsal skin hypopigmentation [39, 40], skin atrophy [41] and plantar fat pad atrophy [39] 3 months after a corticosteroid injection.

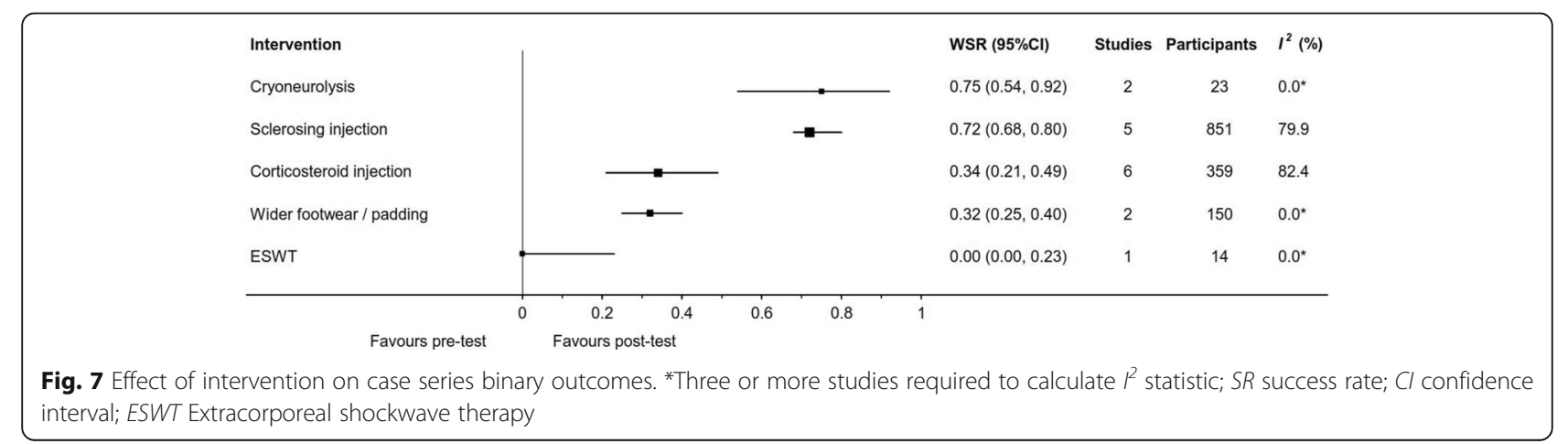




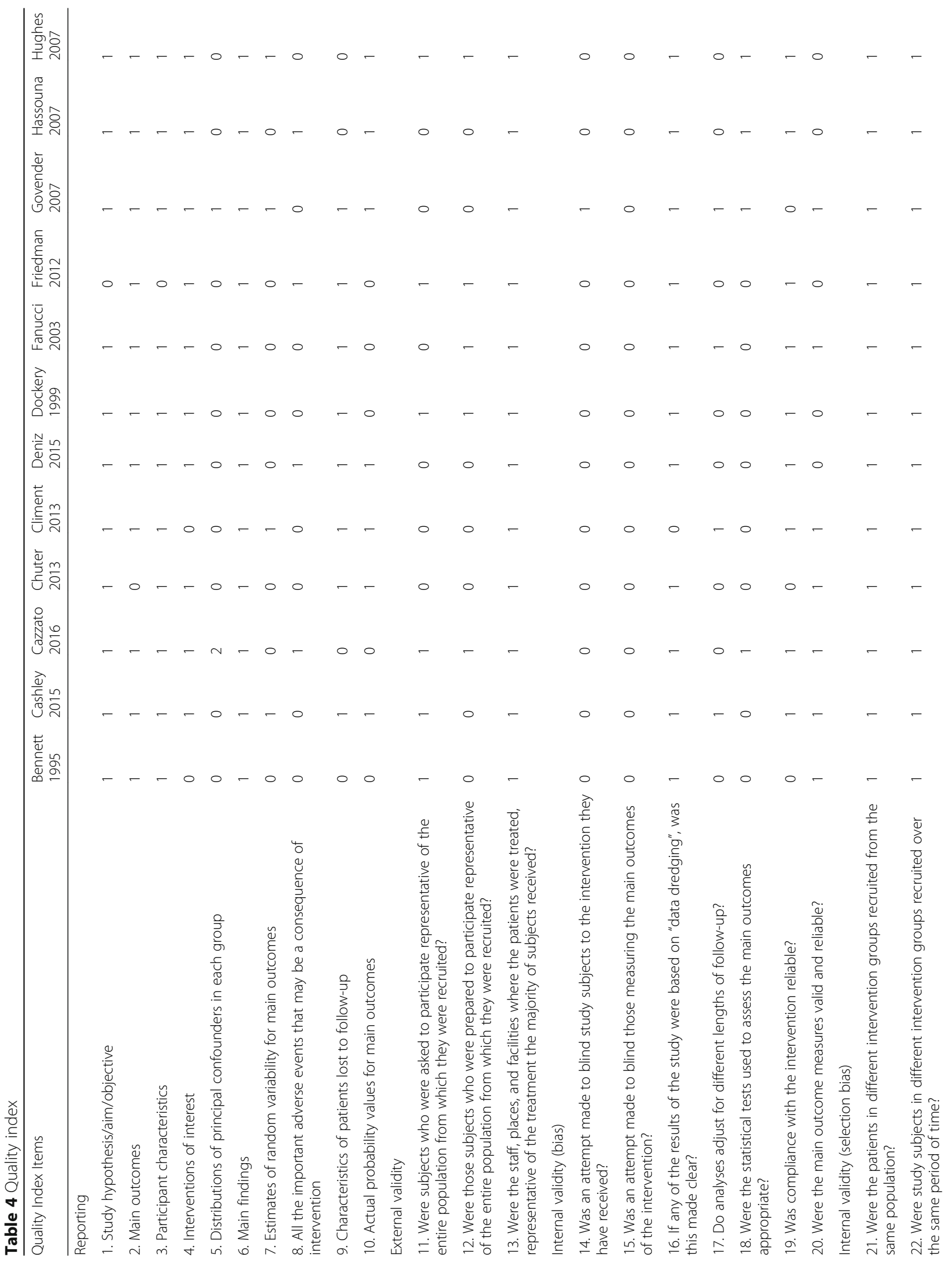




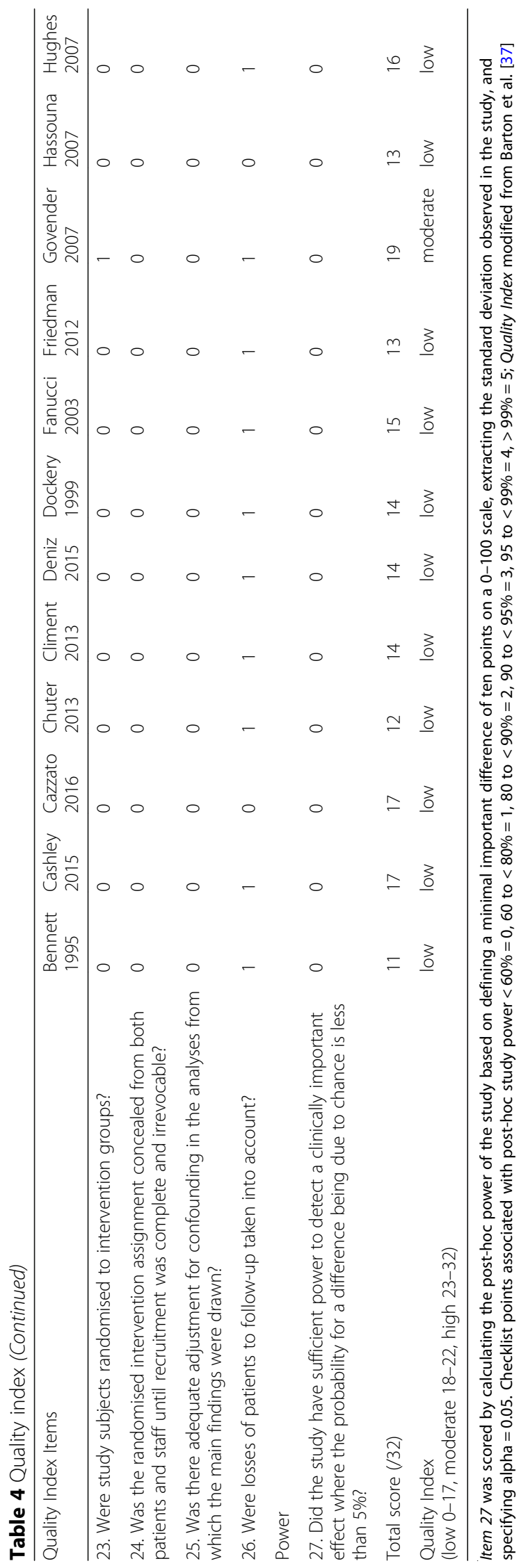




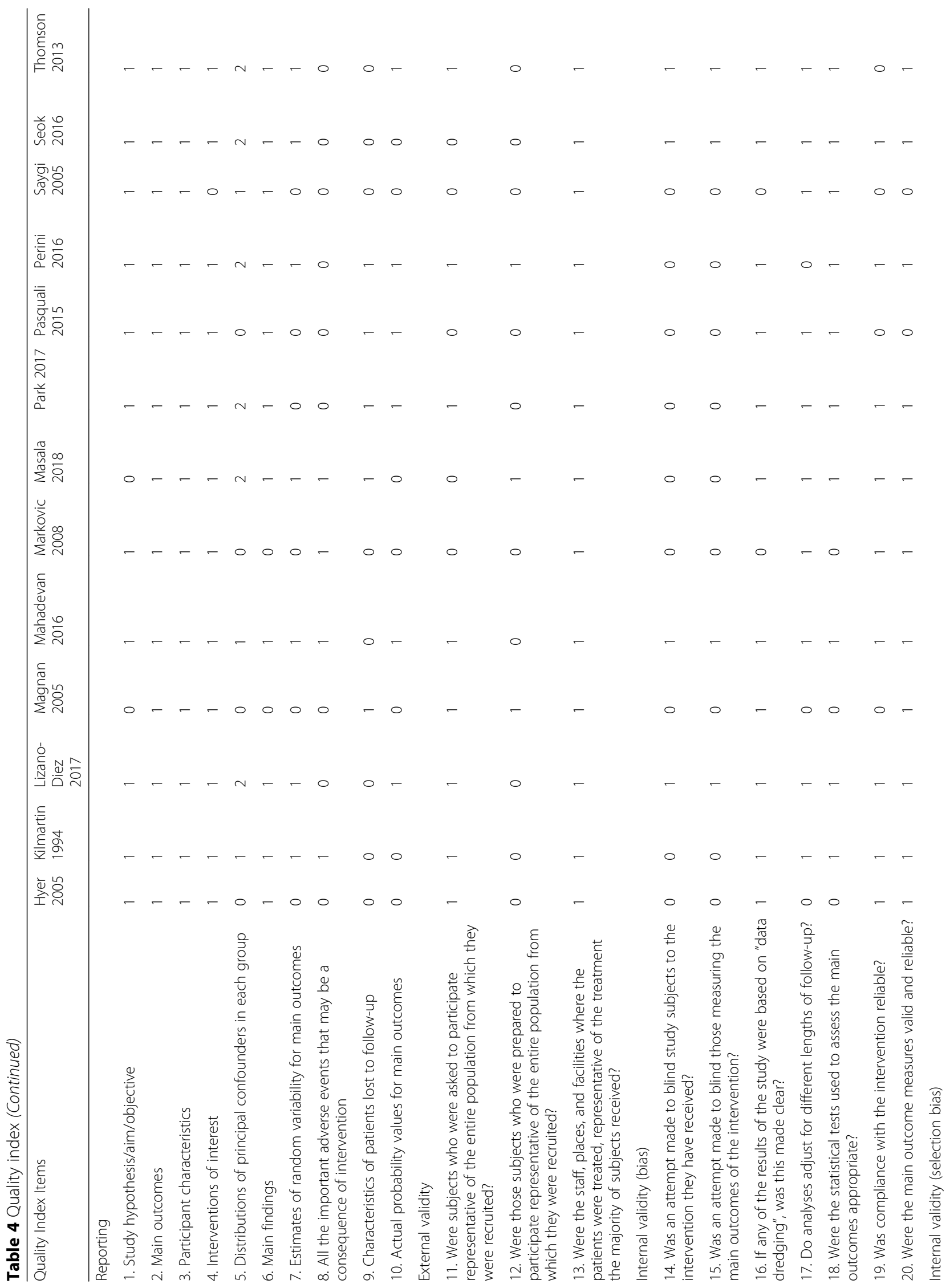




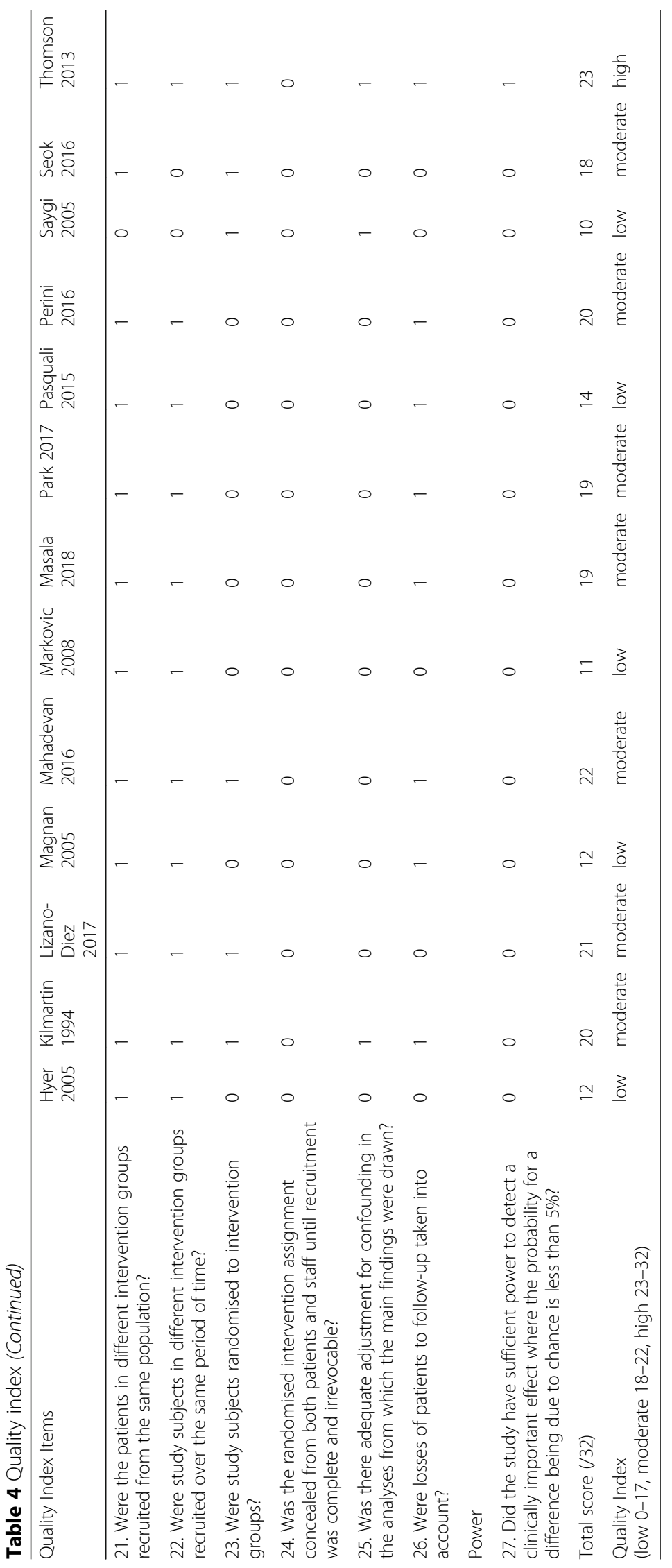




\section{Discussion}

This systematic review evaluated non-surgical interventions for $\mathrm{MN}$, including a wide range of study types to assist clinicians in their evidence-based management of $\mathrm{MN}$ and to inform the future direction of research. The review identified seven RCTs [3, 39-41, 48, 50, 52] and 18 case series $[1,2,4-10,19,20,22,23,49,51,53-55]$ with only one high quality RCT [39]. Meta-analysis of two RCTs $[39,41]$ found that corticosteroid injection decreased pain more than control. One RCT [3] showed that corticosteroid injection was superior to footwear and padding when measuring treatment success. Manipulation/mobilisation demonstrated some efficacy when compared to control at 6 weeks in another RCT [48]. Several case series found a reduction in pre/post pain with sclerosing injections $[5,7,8,19,20,23,55]$, radiofrequency ablation $[9,10,53]$, cryoneurolysis $[49,51]$, and Botox injection [6] but these results should be interpreted with caution. No statistically significant reduction in pain was demonstrated by an RCT [52] investigating ESWT compared to control or by another RCT [50] comparing varus/valgus foot wedges.

The meta-analysis of corticosteroid injections combined two RCTs $[39,41]$ which varied in follow-up (3 vs 6 months), number of injections ( 1 vs 3 ) and guidance during injection (UG vs NUG). Six of the studies [1, 3, 22, 40, 41,54 ] had a 6 month or longer follow-up and only one study [39] had a 3 month follow-up (seven studies in total). It is not known whether combining a 3 month difference in follow-up periods affects the quality of the analysis. Five of the seven included studies used one injection [1, 22, 39, $54,56]$, however two published treatment pathways for MN $[26,30]$ state that up to three injections are typically given. Thomas et al. [25], reports multiple injections obtain better results, however this statement is based on low quality studies [3, 4, 59-61]. There is no high-quality evidence for the number of injections or if multiple injections influence the effect size more than one injection. Mahadevan et al. [40], demonstrated there was no statistically significant difference between UG and NUG corticosteroid injections when a trained clinician administered the NUG injection (Figs. 4 and 5). This finding was used to justify combining the two RCTs [39, 41] for the meta-analysis. Neuroma diameter may be a factor in the small reduction in pain reported by the corticosteroid meta-analysis. Mahadevan et al. [56], found that people with neuroma with a transverse diameter larger than $5 \mathrm{~mm}$ had worse pain scores by 6 months post injection compared to those with a smaller neuroma. The mean transverse diameter for Thomson et al. [39], was $9.6 \mathrm{~mm}$ and Lizano-Diez et al. [41], was $8 \mathrm{~mm}$ which were both larger than $5 \mathrm{~mm}$. The follow-up period and number of injections are differences which should be considered when interpreting the small effect size reported in the meta-analysis (Fig. 3).
One RCT of manipulation/mobilisation [48] had the largest mean difference of the included RCTs in the review (Fig. 4). The short follow-up period (1.5 months) compared to the follow-up mean of all the included studies in the review (9.9 months) suggests the result should be interpreted with caution. The intervention involved several manipulations/mobilisations including dorso/plantar glides of one metatarsal relative to the next and distraction and/or plantarflexion of the metatarsophalangeal joints. The common plantar digital nerve is surrounded by concentric layers of fibrous and loose connective tissue which creates a protective tunnel for the nerve to move independently of the surrounding tissue during gait [62]. A proposed pathological process involves the connective tissue becoming thickened and fibrotic in Morton's neuroma [63] changing the protective tunnel into a nerve entrapment with ischemia [62]. Manipulation/mobilisation may reduce pain by decreasing the stiffness in the connective tissue surrounding the nerve.

The studies assessing footwear and padding [3, 4] are of low methodological quality demonstrating small success rates and one RCT [3] showed corticosteroid injections to be more successful than footwear and padding, however it should be considered that there are no adverse events reported with footwear and padding. A metatarsal pad is shaped to fit the plantar aspect of the foot, proximal to the metatarsal heads at the distal border, medially and laterally to the first and fourth intermetatarsal spaces respectively and proximal to the metatarsal bases with the pad thickness reducing distal to proximal and toward the medial and lateral borders. Prefabricated or custom foot orthoses may incorporate a metatarsal pad.

The included sclerosing injection case series $[5,7,8$, $19,20,23,55$ ] encompassed varying frequency of injections ( 1 to 9 injections over a period of up to 3 months) and review periods (6 to 55 months). While the WMD in pain scores and WSR were high (Figs. 6 and 7), the treatment and review variability coupled with only uncontrolled pre/post data provides low quality evidence and an RCT is required to confirm these findings. Three published treatment pathways include sclerosing injections as a second stage intervention $[25,26,28]$, while another three report concern about the lack of high quality evidence [27], adverse events $[29,30]$ or the lack of long term treatment success leading to surgery [29, 30]. Pain during and post injection for up to 21 days was a common short-term adverse event, but no long-term adverse events were reported from 1040 participants with a mean 14.9 months (range 6 to 55) review period. Failure of the sclerosing injection to substantially reduce pain in either the short or long term resulted in 177 (17\%) participants progressing to surgical excision. 
Three pre/post case series investigating radiofrequency ablation $[9,10,53]$ found a large reduction in pain (WMD: -51.7 ; 95\%CI: -77.1 to -26.3 ) (Fig. 6) but an RCT is required to confirm these findings. While radiofrequency ablations have been investigated previously, they have not been included in treatment pathways to date because participants in previously identified radiofrequency ablation studies concurrently received a corticosteroid injection, which made it difficult to separate the benefits of the two interventions [30]. The three new pre/post case series [9, $10,53]$ included in this systematic review are not confounded by additional interventions and demonstrate pain reduction with no long-term adverse events reported.

Kilmartin and Wallace [50], assessed a varus felt wedge to supinate the foot verses a valgus felt wedge to pronate the foot, and reported no statistically significant reduction in pain with either type of wedge. The study tests the hypothesis that a supinated subtalar joint would reduce forefoot abduction, reducing $\mathrm{MN}$ compression and pain. This hypothesis, based on the Root model of foot function, assumes that pronation of the foot during the propulsive phase of gait causes the metatarsals to become unstable, resulting in the metatarsal heads moving laterally, causing a shear force on the plantar soft tissues, resulting in a $\mathrm{MN}$ [64]. The current understanding is that foot orthoses alter the magnitude, timing, and velocity of motion in the foot. In addition to altering kinematics, foot orthoses also alter plantar pressures, muscle activity and kinetics, which can be used to reduce stress on targeted tissues with the intention of reducing the risk of tissue damage [65-68]. The term orthosis used in the study [50] does not represent the current understanding of foot or orthosis function. Therefore, the term "varus/ valgus foot wedge" has been used in this review to represent the intervention used in Kilmartin and Wallace's study. No studies assessing the effect of orthoses on foot function related to $\mathrm{MN}$ were found by the review.

This systematic review provides the most current and comprehensive assessment of non-surgical interventions for MN published to the best of the authors' knowledge. Clinicians and researchers may use the findings as an evidence-based summary to help guide their clinical management and research. The results however, should be interpreted while considering the following limitations. The review only searched for and included studies published in English, excluding non-English language publications. A 2009 RCT comparing ESWT to sham ESWT was not included in this review as the participants mean age and range was not reported [69]. Including this RCT may have altered the results from the data analysis. The Johnson scale [57] was collapsed into binary data, by classifying "satisfied" as success. Regrouping binary data with "satisfied" and "satisfied with minor reservations" as success would increase the success rates reported and modify the results. There is no published minimal important difference for $\mathrm{MN}$ interventions. Therefore, it is unknown whether the small effect sizes reported by RCTs are clinically meaningful. Where enough studies were pooled to calculate an $I^{2}$ statistic with pre/post continuous (Fig. 6) or binary (Fig. 7) outcomes, the values ranged from 79.9 to $99.5 \%$. Higgins et al. [43], showed about a quarter of the meta-analyses in the Cochrane database of systematic reviews have $I^{2}$ values over $50 \%$. Values over $75 \%$ have tentatively been assigned as having high levels of heterogeneity [43]. Where $I^{2}$ values were calculated in this systematic review for pre/post data there were high levels of heterogeneity.

High quality experimental studies investigating non-surgical treatments for $\mathrm{MN}$ are lacking [30, 32, 39], although there has been a small number of RCTs recently published $[40,41,52]$. In particular, future RCTs are needed to evaluate the effectiveness of sclerosing injections, radiofrequency ablations and cryoneurolysis, in order to confirm findings from low quality case series. Using a randomised study design where an intervention group is compared with a control group allows researchers to measure the causal benefit of the intervention. That is, the effect of intervention beyond any placebo effect a sham treatment may have, or beyond any natural improvement with time, which cannot be determined in a pre/post case series. The identification of a minimal important difference for pain improvement [70] would be informative to help clinicians and researchers understand the minimum worthwhile improvement patients report, replacing the range of values demonstrated across three RCTs included in this review [39-41]. When designing experimental studies, consideration should be given to consistent review periods (1, 6 and 12 months), validated outcome measures and the CONSORT guidelines [71] to allow the combining of RCTs for high quality meta-analyses of interventions with the same therapeutic mechanism.

\section{Conclusions}

This review found some evidence of pain reduction following corticosteroid injection or manipulation/mobilisation techniques for MN. However, no high-quality evidence currently exists to inform which intervention should be the gold standard for first- or second-line non-surgical treatments. Further high quality RCTs are warranted to provide a solid evidence base for non-surgical treatment of MN.

\section{Additional file}

Additional file 1: Raw results for outcome measures of included studies. (XLSX $22 \mathrm{~kb})$

\section{Abbreviations}

Cl: Confidence interval; ESWT: Extracorporeal shockwave therapy; MD: Mean difference; MN: Morton's neuroma; NHMRC: Australian National Health and Medical Research Council; NUG: Non-ultrasound guided; OR: Odds ratio; 
PICOS: Population, intervention, comparison, outcome and study type; PRISMA: Preferred reporting items for systematic reviews and meta-analyses; RCT: Randomised controlled trial; SR: Success rate; UG: Ultrasound guided; VAS: Visual analogue scale; WMD: Weighted mean difference; WSR: Weighted success rate

\section{Acknowledgements}

Jennifer Thomas, Queensland University of Technology Library Liaison; for her assistance in designing the search strategy. Adele Thomas for her assistance in translating Filippo Civinini's 1835 anatomy paper from Italian into English.

\section{Funding}

Not applicable.

\section{Availability of data and materials}

Data sharing not applicable to this article as no datasets were generated or analysed during the current study.

\section{Authors' contributions}

$\mathrm{BM}, \mathrm{SH}$ and RW designed the study. BM performed database searches. First search 2016: BM, MH and RH reviewed the studies, second search 2018: BM and MH reviewed the studies. SH resolved disagreements during the review process. BM and RW generated the synthesis of results. BM drafted the manuscript, SH and RW edited the manuscript. All authors read and approved the final manuscript.

\section{Ethics approval and consent to participate}

Not applicable.

\section{Consent for publication}

Not applicable.

\section{Competing interests}

The authors declare that they have no competing interests.

\section{Publisher's Note}

Springer Nature remains neutral with regard to jurisdictional claims in published maps and institutional affiliations.

\section{Author details}

${ }^{1}$ School of Clinical Sciences, Queensland University of Technology, Kelvin Grove, Brisbane, QLD 4059, Australia. ${ }^{2}$ Institute of Health and Biomedical Innovation, Queensland University of Technology, Kelvin Grove, Brisbane, QLD 4059, Australia. ${ }^{3}$ School of Health Sciences, University of South Australia, Adelaide, SA 5000, Australia. ${ }^{4}$ Rachel Henry Podiatry, Clayfield, Brisbane, QLD 4011, Australia. ${ }^{5}$ Menzies Health Institute Queensland, Griffith University, Nathan, Brisbane, QLD 4111, Australia.

\section{Received: 11 June 2018 Accepted: 29 January 2019} Published online: 13 February 2019

\section{References}

1. Markovic M, Chrichton K, Read JW, Lam P, Slater HK. Effectiveness of ultrasound-guided corticosteroid injection in the treatment of Morton's neuroma. Foot Ankle Int. 2008;29:483-7.

2. Cashley DG, Cochrane L. Manipulation in the treatment of plantar digital neuralgia: a retrospective study of 38 cases. J Chiropr Med. 2015;14:90-8.

3. Saygi B, Yildirim Y, Saygi EK, Kara H, Esemenli T. Morton neuroma: comparative results of two conservative methods. Foot Ankle Int. 2005;26: 556-9.

4. Bennett GL, Graham CE, Mauldin DM. Morton's interdigital neuroma: a comprehensive treatment protocol. Foot Ankle Int. 1995;16:760-3.

5. Dockery GL. The treatment of intermetatarsal neuromas with $4 \%$ alcohol sclerosing injections. J Foot Ankle Surg. 1999;38:403-8.

6. Climent JM, Mondejar-Gomez F, Rodriguez-Ruiz C, Diaz-Llopis I, GomezGallego D, Martin-Medina P. Treatment of Morton neuroma with botulinum toxin a: a pilot study. Clin Drug Investig. 2013;33:497-503.

7. Hughes RJ, Ali K, Jones H, Kendall S, Connell DA. Treatment of Morton's neuroma with alcohol injection under sonographic guidance: follow-up of 101 cases. AJR Am J Roentgenol. 2007;188:1535-9.

8. Pasquali C, Vulcano E, Novario R, Varotto D, Montoli C, Volpe A. Ultrasoundguided alcohol injection for Morton's neuroma. Foot Ankle Int. 2015;36:55-9.
9. Deniz S, Purtuloglu T, Tekindur S, Cansiz KH, Yetim M, Kılıckaya O, et al. Ultrasound-guided pulsed radio frequency treatment in Morton's neuroma. J Am Podiatr Med Assoc. 2015;105:302-6.

10. Chuter GSJ, Chua YP, Connell DA, Blackney MC. Ultrasound-guided radiofrequency ablation in the management of interdigital (Morton's) neuroma. Skelet Radiol. 2013:42:107-11.

11. Pasero G, Marson P. Filippo Civinini (1805-1844) and the discovery of plantar neuroma. Reumatismo. 2006:58:319-22.

12. Durlacher L. A treatise on corns, bunions, the disease of nails, and the general management of the feet. London: Simpkin, Marshall and Co; 1845.

13. Morton T. A peculiar and painful affection of the fourth metatarsophalangeal articulation. Am J Med Sci. 1876;71:37-45.

14. Latinovic R, Gulliford MC, Hughes RA. Incidence of common compressive neuropathies in primary care. J Neurol Neurosurg Psychiatry. 2006;77:263-5.

15. Mahadevan D, Venkatesan M, Bhatt R, Bhatia M. Diagnostic accuracy of clinical tests for Morton's neuroma compared with ultrasonography. J Foot Ankle Surg. 2015:54:549-53.

16. Owens R, Gougoulias N, Guthrie H, Sakellariou A. Morton's neuroma: clinical testing and imaging in 76 feet, compared to a control group. Foot Ankle Surg. 2011;17:197-200

17. Bignotti B, Signori A, Sormani MP, Molfetta L, Martinoli C, Tagliafico A. Ultrasound versus magnetic resonance imaging for Morton neuroma: systematic review and meta-analysis. Eur Radiol. 2015;25:2254-62.

18. Symeonidis PD, Iselin LD, Simmons N, Fowler S, Dracopoulos G, Stavrou P. Prevalence of interdigital nerve enlargements in an asymptomatic population. Foot Ankle Int. 2012;33:543-7.

19. Hyer CF, Mehl LR, Block AJ, Vancourt RB. Treatment of recalcitrant intermetatarsal neuroma with $4 \%$ sclerosing alcohol injection: a pilot study. J Foot Ankle Surg. 2005;44:287-91.

20. Fanucci E, Masala S, Fabiano S, Perugia D, Squillaci E, Varrucciu V, et al. Treatment of intermetatarsal Morton's neuroma with alcohol injection under US guide: 10-month follow-up. Eur Radiol. 2004;14:514-8.

21. Larson EE, Barrett SL, Battiston B, Maloney CT Jr, Dellon AL. Accurate nomenclature for forefoot nerve entrapment: a historical perspective. J Am Podiatr Med Assoc. 2005;95:298-306.

22. Hassouna $H$, Singh D, Taylor $H$, Johnson S. Ultrasound guided steroid injection in the treatment of interdigital neuralgia. Acta Orthop Belg. 2007;73:224-9.

23. Magnan B, Marangon A, Frigo A, Bartolozzi P. Local phenol injection in the treatment of interdigital neuritis of the foot (Morton's neuroma). Chir Organi Mov. 2005;90:371-7.

24. Levitsky KA, Alman BA, Jevsevar DS, Morehead J. Digital nerves of the foot: anatomic variations and implications regarding the pathogenesis of interdigital neuroma. Foot Ankle. 1993;14:208-14.

25. Thomas JL, ELt B, Chaney DM, Dinucci KA, Eickmeier K, Rubin LG, Stapp MD, Vanore JV. Diagnosis and treatment of forefoot disorders. Section 3. Morton's intermetatarsal neuroma. J Foot Ankle Surg. 2009;48:251-6.

26. Adams WR 2nd. Morton's neuroma. Clin Podiatr Med Surg. 2010;27:535-45.

27. Schreiber K, Khodaee M, Poddar S, Tweed EM, Inquiry C. What is the best way to treat Morton's neuroma? J Fam Pract. 2011;60:157-68.

28. DiPreta JA. Metatarsalgia, lesser toe deformities, and associated disorders of the forefoot. Med Clin North Am. 2014:98:233-51.

29. Di Caprio F, Meringolo R, Shehab Eddine M, Ponziani L. Morton's interdigital neuroma of the foot. A literature review. Foot Ankle Surg. 2018. https://doi. org/10.1016/j.fas.2017.01.007.

30. Jain S, Mannan K. The diagnosis and management of Morton's neuroma: a literature review. Foot Ankle Spec. 2013;6:307-17.

31. Thomson CE, Gibson JN, Martin D. Interventions for the treatment of Morton's neuroma. Cochrane Database Syst Rev. 2004. https://doi.org/10. 1002/14651858.CD003118.pub2.

32. Valisena S, Petri GJ, Ferrero A. Treatment of Morton's neuroma: a systematic review. Foot Ankle Surg. 2017. https://doi.org/10.1016/j.fas.2017.03.010.

33. Macquarie Dictionary Online, 2016, Macquarie Dictionary Publishers, an imprint of Pan Macmillan Australia Pty Ltd. http://www.macquariedictionary. com.au. Accessed 3 Feb 2019.

34. Merlin T, Weston A, Tooher R. Extending an evidence hierarchy to include topics other than treatment: revising the Australian 'levels of evidence'. BMC Med Res Methodol. 2009;9:34.

35. Liberati A, Altman DG, Tetzlaff J, Mulrow C, Gotzsche PC, loannidis JP, et al. The PRISMA statement for reporting systematic reviews and meta-analyses of studies that evaluate health care interventions: explanation and elaboration. PLoS Med. 2009. https://doi.org/10.1371/journal.pmed.1000100. 
36. Downs SH, Black N. The feasibility of creating a checklist for the assessment of the methodological quality both of randomised and non-randomised studies of health care interventions. J Epidemiol Community Health. 1998; 52:377-84.

37. Barton CJ, Bonanno DR, Carr J, Neal BS, Malliaras P, Franklyn-Miller A, et al. Running retraining to treat lower limb injuries: a mixed-methods study of current evidence synthesised with expert opinion. Br J Sports Med. 2016;50:513-26.

38. Cumming J. Does anyone have specific guidance for how to interpret question 27 (power) of the Downs and Black (1998) checklist? https://www. researchgate.net/post/Does_anyone_have_specific_guidance_for_how_to_ interpret_question_27_power_of_the_Downs_and_Black_1998_checklist. Accessed 3 Feb 2019.

39. Thomson CE, Beggs I, Martin DJ, McMillan D, Edwards RT, Russell D, et al. Methylprednisolone injections for the treatment of Morton neuroma: a patient-blinded randomized trial. J Bone Joint Surg Am. 2013;95:790-8.

40. Mahadevan D, Attwal M, Bhatt R, Bhatia M. Corticosteroid injection for Morton's neuroma with or without ultrasound guidance: a randomised controlled trial. Bone Joint J. 2016;98B:498-503.

41. Lizano-Diez X, Gines-Cespedosa A, Alentorn-Geli E, Perez-Prieto D, GonzalezLucena G, Gamba C, et al. Corticosteroid injection for the treatment of Morton's neuroma: a prospective, double-blinded, randomized, placebocontrolled trial. Foot Ankle Int. 2017;38:944-51.

42. Scott J, Huskisson EC. Graphic representation of pain. Pain. 1976;2:175-84.

43. Higgins JP, Thompson SG, Deeks JJ, Altman DG. Measuring inconsistency in meta-analyses. Br Med J. 2003;327:557-60.

44. MacDougall-Davis SR, Kettley L, Cook TM. The 'go-between' study: a simulation study comparing the 'Traffic Lights' and 'SBAR' tools as a means of communication between anaesthetic staff. Anaesthesia. 2016;71:764-72.

45. Phillips $P$, Evans AM. One pair must last a lifetime. Foot care in diabetes. Aust Fam Physician. 2002;31:741-4.

46. Evans AM. The flat-footed child -- to treat or not to treat: what is the clinician to do? J Am Podiatr Med Assoc. 2008;98:386-93.

47. Sackett DL, Rosenberg WM, Gray JA, Haynes RB, Richardson WS. Evidence based medicine: what it is and what it isn't. Br Med J. 1996;312:71-2.

48. Govender N, Kretzmann H, Price JL, Brantingham JW, Globe G. A singleblinded randomized placebo-controlled clinical trial of manipulation and mobilization in the treatment of Morton's neuroma. J Am Chiropr Assoc. 2007;44:8-18.

49. Friedman T, Richman D, Adler R. Sonographically guided cryoneurolysis: preliminary experience and clinical outcomes. J Ultrasound Med. 2012;31: 2025-34.

50. Kilmartin TE, Wallace WA. Effect of pronation and supination orthosis on Morton's neuroma and lower extremity function. Foot Ankle Int. 1994;15:256-62.

51. Cazzato RL, Garnon J, Ramamurthy N, Tsoumakidou G, Caudrelier J, Thenint MA, et al. Percutaneous MR-guided Cryoablation of Morton's neuroma: rationale and technical details after the first 20 patients. Cardiovasc Intervent Radiol. 2016;39:1491-8.

52. Seok H, Sang-Hyun K, Seung Yeol L, Sung Won P. Extracorporeal shockwave therapy in patients with Morton's neuroma. J Am Podiatr Med Assoc. 2016; 106:93-9.

53. Masala S, Cuzzolino A, Morini M, Raguso M, Fiori R. Ultrasound-guided percutaneous radiofrequency for the treatment of Morton's neuroma. Cardiovasc Intervent Radiol. 2018;41:137-44.

54. Park YH, Lee JW, Choi GW, Kim HJ. Risk factors and the associated cutoff values for failure of corticosteroid injection in treatment of Morton's neuroma. Int Orthop. 2017.

55. Perini $L$, Perini C, Tagliapietra M, Varotto D, Valcarenghi A, Postorino A, et al. Percutaneous alcohol injection under sonographic guidance in Morton's neuroma: follow-up in 220 treated lesions. Radiol Med. 2016;121:597-604.

56. Mahadevan D, Salmasi M, Whybra N, Nanda A, Gaba S, Mangwani J. What factors predict the need for further intervention following corticosteroid injection of Morton's neuroma? Foot Ankle Surg. 2016;22:9-11.

57. Johnson JE, Johnson KA, Unni KK. Persistent pain after excision of an interdigital neuroma. Results of reoperation. J Bone Joint Surg Am. 1988;70:651-7.

58. Sobiesk GA, Wertheimer SJ, Schulz R, Dalfovo M. Sonographic evaluation of interdigital neuromas. J Foot Ankle Surg. 1997;36:364-6.

59. Greenfield J, Rea J Jr, llfeld FW. Morton's interdigital neuroma. Indications for treatment by local injections versus surgery. Clin Orthop Relat Res. 1984; $185: 142-4$.
60. Rassmussen MR, Kitaoka HB, Pantzer GL. Nonoperative treatment of plantar interdigital neuroma with single corticosteroid injection. Clin Orthop Relat Res. 1996;326:188-93.

61. Strong G, Thomas PS. Conservative treatment of Morton's neuroma. Orthop Rev. 1987;16:343-5.

62. Stecco C, Fantoni I, Macchi V, Del Borrello M, Porzionato A, Biz C, et al. The role of fasciae in Civinini-Morton's syndrome. J Anat. 2015;227:654-64.

63. Giakoumis M, Ryan JD, Jani J. Histologic evaluation of intermetatarsal Morton's neuroma. J Am Podiatr Med Assoc. 2013;103:218-22.

64. Root $M$, Orein W, Weed J. Normal and abnormal function of the foot. 1st. Los Angeles: Clinical Biomechanics Corporation; 1977.

65. Noakes H, Payne C. The reliability of the manual supination resistance test. J Am Podiatr Med Assoc. 2003;93:185-9.

66. Kirby K. Emerging concepts in podiatric biomechanics. Podiatry Today. 2006; 19:36-48.

67. McPoil TG, Hunt GC. Evaluation and management of foot and ankle disorders: present problems and future directions. J Orthop Sports Phys Ther. 1995;21:381-8.

68. Jarvis HL, Nester CJ, Bowden PD, Jones RK. Challenging the foundations of the clinical model of foot function: further evidence that the root model assessments fail to appropriately classify foot function. J Foot Ankle Res. 2017:10:7.

69. Fridman R, Cain JD, Weil L Jr. Extracorporeal shockwave therapy for interdigital neuroma. J Am Podiatr Med Assoc. 2009;99:191-3.

70. Revicki D, Hays RD, Cella D, Sloan J. Recommended methods for determining responsiveness and minimally important differences for patient-reported outcomes. J Clin Epidemiol. 2008;61:102-9.

71. Moher D, Hopewell S, Schulz KF, Montori V, Gotzsche PC, Devereaux PJ, et al. CONSORT 2010 explanation and elaboration: updated guidelines for reporting parallel group randomised trials. Br Med J. 2010;340.

\section{Ready to submit your research? Choose BMC and benefit from:}

- fast, convenient online submission

- thorough peer review by experienced researchers in your field

- rapid publication on acceptance

- support for research data, including large and complex data types

- gold Open Access which fosters wider collaboration and increased citations

- maximum visibility for your research: over $100 \mathrm{M}$ website views per year

At BMC, research is always in progress.

Learn more biomedcentral.com/submissions 